\title{
ATERRADOS, SACADOS Y (DES)ENTERRADOS: UNA MIRADA ARQUEO- LÓGICA A LOS PAISAJES DEL TERROR CALIENTE DE 1936 EN TIERRAS DE CASTILLA
}

\author{
Juan Montero Gutiérrez ${ }^{(1)}$, Paula Alberdi Díez ${ }^{(2)}$, \\ Sandra Albo Basurto ${ }^{(3)}$ y Natalia García Redondo(4)
}

\section{Resumen:}

Las sacas constituyen el ejemplo más claro de la dimensión mortífera que alcanzaron las prácticas represivas cometidas en la retaguardia franquista a comienzos de la Guerra Civil. Siguiendo el rastro de las mismas dejado en diversas fosas excavadas en la provincia de Burgos, nos planteamos aproximarnos, por un lado, al modus operandi y, por otro, a los paisajes que acogieron estas ejecuciones masivas tan escasamente estudiados desde la perspectiva arqueológica.

\section{Palabras clave:}

Arqueología del Conflicto; Fosa común; Paisaje de terror; Violencia; Saca.

\section{Abstract:}

Removal of prisioners (sacas in Spanish) is the clearest example of the repressive acts committed on the Francoist rearguard at the beginning of the Spanish Civil War. Precisely, the main aim of this paper is, on the one hand, to analyse the modus operandi followed by the rebel forces for removing and killing hundreds of prisoners considered Republican sympathizers, and on the other hand to examine the terror landscapes where this kind of mass executions took place. For this, we will focus on results of different mass graves excavated in the Castilian province of Burgos.

\section{Key words:}

Conflict Archaeology; Mass Grave; Terror Landscape; Violence; Removal.

\section{Introducción}

En la Guerra Civil española, como en todo conflicto bélico contemporáneo, hubo cruentos episodios, si bien estos tuvieron que ver, más que con los combates entre las facciones enfrentadas en los campos de batalla, con la represión des-

1 Arqueólogo. arqueo.montero@gmail.com

2 Arqueóloga. adpaula89@hotmail.com

3 Historiadora. sandra_albo@hotmail.com

4 Arqueóloga. nataliagarcia783@gmail.com

Revista Otarq - ISSN 2530-4933

Vol. 2 2017, pp. 183-204 
atada en sendas retaguardias. Sabido es la extrema violencia empleada por unos y otros en los meses siguientes al fallido golpe militar dado a comienzos del estío de 1936. Y es que no hay ningún tema tan debatido en los últimos años dentro del ámbito académico como éste, al tiempo que tan abierto a la opinión pública y tal vez, por ello, tan tendente a simplificadas (re)interpretaciones ${ }^{5}$.

Un interés, todo hay que decirlo, acentuado por el impacto que ha tenido, de un tiempo a esta parte, el movimiento social por la «recuperación de la memoria histórica» y, particularmente, la visibilidad del drama de los afectados por la represión franquista que, tal y como reconoce buena parte de la comunidad científica, viene derivada, a su vez, de las exhumaciones. De hecho, la fecunda y heterogénea producción bibliográfica, junto con la prolífera celebración de coloquios ya sean de un acusado perfil academicista o de carácter divulgativo, pero en todo caso al socaire, la mayoría de ellos, de este fenómeno, es la prueba palpable del inusitado interés que suscita, hoy por hoy, el tema señalado.

Pero más allá de esto, el hecho cierto es que fue un período en los que unos y otros se empeñaron en suprimir al adversario, empleando para ello métodos represivos inequívocamente semejantes. Ahora bien, cuestión distinta es que difiriese el alcance y la dinámica que tuvo la de los sublevados, a la sazón, los vencedores, respecto a la del lado republicano. Y no sólo nos referimos a las consabidas cifras globales de víctimas que evidencian una más que manifiesta desproporción $^{6}$, sino también al componente planificador ${ }^{7}$. En esencia, esto tiene que ver con la orquestación de una metódica y expeditiva limpieza ideológica por parte de los altos mandos militares sublevados que para llevarla a cabo implantaron una cultura del terror en las zonas donde inicialmente se habían adherido a lo que dieron en llamar el «Alzamiento Nacional» como en las que posteriormente fueron «liberadas». No cabe duda de que esto no relativiza o atenúa, en modo alguno, el «terror rojo» que se produjo en la zona republicana, en buena medida explicable por un enraizado anticlericalismo que hizo que la violencia revolucionaria fuese particularmente intensa no sólo en el Madrid sitiado, sino, muy especialmente, en el Bajo Aragón y Cataluña.

En el caso de Burgos también se dejaron sentir las consecuencias traumáticas de aquel verano caliente del 36, y eso, a pesar de que el conglomerado de fuerzas golpistas se hizo rápidamente con el control, toda vez que apenas encontraron re-

5 G. GÓMEZ BRAVO y A. PÉREZ-OLIVARES: "Las lógicas de la violencia en la Guerra Civil: balance y perspectivas historiográficas". Studia Historica. Historia Contemporánea, 32 (2014), pp. 251-262.

6 P. PRESTON: El holocausto español. Odio y exterminio en la Guerra Civil y después. Debate, Barcelona: 2011, p. 24.

7 F. ESPINOSA MAESTRE: "Julio de 1936. Golpe militar y plan de exterminio" en J. CASANOVA RUIZ (coord): Morir, matar, sobrevivir. La violencia en la dictadura de Franco. Crítica, Barcelona: 2002, pp. 51-119. 
sistencia alguna; con la salvedad de la franja septentrional donde se estabilizaría el frente hasta su caída en agosto de 1937. Ello, no obstante, no deja de ser hasta cierto punto llamativo, pues en esos mismos albures iniciales se constituyó, en la capital castellana, la Junta de Defensa Nacional de los sublevados por razones evidentemente estratégicas a la luz del mapa resultante tras el fracaso del «pronunciamiento", pero también por el masivo apoyo que recibieron por estos lares; luego, como bien se sabe, terminaría albergando la sede del Gobierno de Franco, lo que le valió el reconocimiento de capitalidad de la «Cruzada» ${ }^{8}$.

Sin embargo, no es nada extraño que la provincia burgalesa, en línea con lo acontecido en otras partes de la España Nacional, fuese también escenario de una brutal represión, incluidas matanzas masivas. Prueba de ello es que, lejos de tener escasa incidencia, hubo un gran número de víctimas mortales entre aqueIlos burgaleses que fueron tachados denigratoriamente de «rojos». De hecho, se estima que pudo haber en torno a 2.500 en toda la provincia de Burgos ${ }^{9}$. Cuantificaciones aparte, lo cierto es que, como resultado de todo ello, las fosas comunes se extienden por toda la geografía burgalesa, tal como vienen evidenciando las numerosas exhumaciones realizadas desde hace más de una década.

Por eso nos planteamos en este trabajo volver la mirada hacia una de esas acciones de extrema violencia que se cometieron de forma sistemática durante los primeros meses de la contienda. Nos referimos, concretamente, a las «sacas». Para ello y tomando como base diversas fosas excavadas en tierras burgalesas, nos proponemos trazar un análisis de los principales escenarios que acogieron este tipo de ejecuciones irradiadas desde diversos centros de confinamiento de la capital como de otras localidades menores de la provincia. Conviene matizar que, en algunos casos, se trataba de penales oficiales, pero, en otros muchos, de cárceles improvisadas. De modo que entre los objetivos añadidos está comparar diferentes episodios de sacas a fin de analizar si se siguieron modus operandi dispares en función o no de la procedencia, además de otros factores que ayuden a explicar el sentido que adquirió el paisaje, entendido en términos de una topografía del terror.

\section{No es país para rojos}

A escala de la provincia de Burgos es bien conocido el discurrir de la Guerra Civil o, mejor dicho, el ambiente cotidiano que se vivió en una zona relativamente alejada de la contienda, ya por entonces bendecida por la jerarquía eclesiástica, de ahí que se tildase de «Santa Cruzada». Ésta, a decir verdad, se veía como

8 L. CASTRO BERROJO: Capital de la Cruzada. Burgos durante la Guerra Civil. Crítica, Barcelona: 2006.

9 Ibidem, p. 252. 
algo poco amenazante, a pesar de algunos bombardeos ocasionales de la aviación republicana sobre algunos núcleos burgaleses o de los infructuosos intentos por romper las líneas en el Frente Norte. Precisamente por ello se simultaneaban las entusiastas muestras de adhesión al "Glorioso Movimiento" por parte de numerosos vecinos afines a la derecha castellana más tradicionalista, con el ejercicio continuado de la represión impuesto por las autoridades militares sobre otra parte de la población que encarnaba, ciertamente, otros ideales bien diferentes.

Nada nuevo añadimos, por tanto, si decimos que la fuerza armada tuvo en las milicias adeptas de falangistas, requetés y, en el caso particular de la capital burgalesa, a los conocidos como legionarios de Albiñana ${ }^{10}$, a sus principales brazos ejecutores. O que los primeros objetivos en ser señalados por mandato del «director» del golpe, el general Mola, fueron los dirigentes políticos que, en los meses precedentes, habían ostentado algún cargo electo bajo las siglas de la coalición del Frente Popular. Baste recordar los célebres bandos de guerra emitidos a comienzos de la contienda. Así, alcaldes y concejales de las comisiones gestoras que regían los ayuntamientos desde febrero de 1936 fueron inmediatamente depuestos y luego arrestados o viceversa; lo que se haría extensible a los miembros de la Diputación Provincial. Pero no solo ellos. También los líderes y afiliados de organizaciones sindicales izquierdistas $y$, en definitiva, cualquiera que fuese considerado simpatizante de la República y, por tanto, «rojo»o, su equivalente, «antiespañol»; y aquí el decálogo alcanzaba a numerosos intelectuales y a no pocos ciudadanos entre reconocidos masones como también declarados ateos.

Todo ello da idea de que la motivación ideológica o, lo que es lo mismo, la identidad política, fue el elemento diferenciador, esto es, la premisa a la hora de acometer las tareas de limpieza, lo que desmonta aquellas explicaciones que apelaban a los rencores de unos sujetos incontrolados que actuaron de forma espontánea, tan reiteradamente argüidos por ciertos sectores de la historiografía tardo-franquista. No obstante, es evidente que las dinámicas intracomunitarias juegan un papel decisivo a la hora de comprender ciertas lógicas empleadas para arrestar y/o matar a según quien.

Con esto no pretendemos incidir en la citada cuestión de las rencillas y envidias locales como argumento esencial de las causas y efectos que tuvo el empleo de una violencia extrema. Sin embargo, no es menos cierto que a partir del análisis de las circunstancias que rodearon los meses o, inclusive, los años previos al estallido de la guerra, es posible atisbar cómo se engendró el odio visceral hacia el contrario que habría de terminar cristalizando en el clima opresivo que aquí nos

10 José María Albiñana Sanz (1883-1936) era diputado por el Partido Nacionalista Español, habiendo salido elegido en la provincia de Burgos a pesar de no tener ningún tipo de vínculo con esta tierra. Se encontraba en Madrid cuando se dio el golpe por lo que fue inmediatamente detenido y encarcelado por las autoridades republicanas, siendo asesinado el 23 de agosto de 1936 tras el asalto a la cárcel Modelo. 
proponemos explorar. Pero insistimos, una vez más, que la implicación en ellos de los vecinos de los ámbitos sobre todo rurales, ya fuese afiliándose a la milicia de Falange o al Requeté local, bien contribuyendo de forma activa en las tareas delatoras y requisatorias, o sencillamente adoptando una postura silente que no eximía de complicidad, no se explica sin el apoyo y aprobación expresa de las autoridades militares que dictaminaron qué se podía o no hacer, aparte de cuándo y cómo debía ejecutarse y, naturalmente, quiénes habrían de ser aniquilados ${ }^{11}$.

Porque lo que estableció la diferencia, a fin de cuentas, en lo referido a las brutales prácticas represivas cometidas tras el 17 de julio de 1936 fue el hecho, incuestionable, de que se diese un golpe de estado, Ilámese sublevación militar o, en terminología de la época, un «alzamiento». Y quienes lo idearon y ejecutaron aceptaban la expeditiva y sistemática eliminación del otro como medio lícito, además de verlo como algo sumamente necesario, tal y como dejaron claro a través de los consabidos bandos y arengas radiofónicas. De ahí que la intervención armada estuviese abanderada no sólo por las fuerzas militares sino también por los grupos de milicianos, Ilamémosles, paramilitares que consiguieron movilizar para que acudiesen al frente, pero también para mantener el orden en muchos pueblos de la retaguardia franquista, donde serían, a la postre, los catalizadores de las acciones violentas. Eso sí, a los más radicales les moverá, más que a nadie, el afán aniquilador bajo el síndrome evidente de una cruel indiferencia, no exenta de cierta dimensión placentera, propia, desde luego, de una patología homicida.

De modo que, en aquellos primeros días, se sucedieron las denuncias y redadas, previa configuración de listas negras, las confiscaciones de bienes y el desvalijamiento e incautación de locales, la requisa de armas, y paralelamente los primeros «paseos» con cadáveres abandonados a las afueras de muchas localidades o en las propias calles de Burgos, tal como pudo comprobar Antonio Ruiz Vilaplana que, por entonces, ejercía allí como secretario judicial. Precisamente, su tarea de tener que acudir a los lugares donde se hallaban los cuerpos para proceder al correspondiente levantamiento de los mismos sirvió de título a su obra, Doy fe..., acaso uno de los testimonios más desgarradores y fidedignos de las atrocidades cometidas en la España «nacionalista» ${ }^{12}$.

$Y$ todo ello en un ambiente marcado por una mezcolanza de inusitada incredulidad y un miedo atroz, este último acrecentado, aún más si cabe, por el continuo ingreso de «desafectos» en los penales burgaleses, lo que producía la consiguiente inquietud de los familiares. En este sentido, bien podemos decir que de la incompren-

11 C. GIL ANDRÉS: "También hombres del pueblo. Colaboración ciudadana en la gran represión" en M.A. DEL ARCO, C. FUENTES, C. HERNÁNDEZ y J. MARCO (eds): No solo miedo. Actitudes políticas y opinión popular bajo la Dictadura Franquista (1936-1977). Comares Historia, Granada: 2013, pp. 52-53.

12 F. ESPINOSA MAESTRE y L. CASTRO BERROJO: "Prólogo" en A. RUIZ VILAPLANA: Doy fe... Un año de actuación en la España nacionalista. Espuela de Plata, Sevilla: 2012, pp. 11-49. 
sión inicial -como si lo ocurrido hubiera sido un equívoco, pues confiaban en que no habían hecho nada- se pasó, inmediatamente, a la angustia y el desconsuelo de ver como el confinamiento se alargaba en el tiempo. Pero de ahí a que se desatase un dolor sine die por la pérdida o desaparición de parientes y allegados, apenas transcurrió mucho tiempo. Exactamente el que medió hasta que un día que visitaban el penal correspondiente les comunicaron que ya no hacía falta que volviesen por allí.

Así las cosas, el elevado número de detenciones practicadas a finales de julio y comienzos de agosto pronto saturaron las prisiones de la capital burgalesa, tanto la Central como la Provincial; esta última, por cierto, albergaba mujeres, además de hombres. Y es que no sólo eran recluidos en ellas los oriundos de la caput castellae, sino también muchos otros que procedían de comarcas como la Bureba, Merindades, Odra-Pisuerga, Pinares, Ribera del Duero, Valle del Arlanza, o núcleos tan significativos como Aranda de Duero y Miranda de Ebro, donde en esos momentos también se estaban produciendo arrestos masivos. Sirva de ejemplo que por la Prisión Central de Burgos Ilegaron a pasar, hasta diciembre de 1936, un total de 882 reclusos, siendo 235 vecinos de Burgos y 647 naturales de otros puntos de la provincia como los mencionados ${ }^{13}$.

Otros, en cambio, permanecieron en sus localidades de origen, pues es allí donde se les tomó declaración, siendo así confinados en cárceles habilitadas en edificios que, por lo general, albergaban dependencias municipales, tal y como ocurrió en Aranda de Duero, Briviesca, Lerma, Salas de los Infantes y en tantos otros municipios del ámbito rural burgalés, particularmente cabeceras de comarca. Casi la totalidad de ellos terminarían siendo asesinados en las semanas siguientes, producto de sacas como tendremos ocasión de ver más adelante.

Cierto es que entre los detenidos en los penales oficiales de la capital habrá quienes, sin necesidad de juicio previo, recobren pronto la libertad gracias, en muchos casos, a la intermediación que conseguirán los familiares de influyentes derechistas que avalarán, mediante cartas favorables o informes exculpatorios que estos tenían una conducta y moralidad intachable, así como que carecían de vinculación política alguna con organizaciones izquierdistas; o quienes, por el contrario, inicien largos cautiverios hasta su definitiva liberación, algunos en el período de la posguerra, eso sí, soportando todo tipo de castigos, incluidas palizas y torturas, además de hambre, frío, hacinamiento y, producto de todo ello, padeciendo múltiples enfermedades que sobre todo tenían que ver con afecciones respiratorias y basculares. Pero también habrá quienes encontrarán la muerte tras ser condenados en un juicio sumarísimo, por lo que serán ejecutados por un pelotón de fusilamiento, o bien creyendo ser liberados y, por tanto, sin mediar sentencia alguna. Son estos últimos en quienes vamos a centrar el foco de atención.

13 I. RILOVA PÉREZ: Guerra Civil y violencia política en Burgos (1936-1943). Dossoles, Burgos: 2001, p. 280. 


\section{Camino a ninguna parte}

Conviene empezar precisando que las sacas consistían, básicamente, en falsas excarcelaciones dictadas por los responsables de las prisiones cuyas órdenes habían recibido, a su vez, de la autoridad militar pertinente. Pero, ¿quién había comunicado a dicho mando del Ejército los nombres que conformaban las fatídicas listas? Sabemos, por expedientes penales que se han conservado en el Centro Penitenciario de Burgos -antigua Prisión Central- que la orden de aprobación o desaprobación emanaba del gobernador civil, el general Fidel Dávila que lo fuera hasta inicios de septiembre y posteriormente el general Francisco Fermoso hasta el 12 de octubre de 1936, tal como denotan sus respectivas rúbricas ${ }^{14}$.

Ahora bien, quienes confeccionaban la relación de nombres eran los integrantes de la Falange o el Requeté de las comarcas de donde procedían los propios reclusos, en connivencia con los nuevos poderes locales; aunque no en todos los casos ni circunstancias. De esta forma terminarían figurando numerados en uno de los márgenes de los oficios que emitía el director del penal, sucesivamente los capitanes Genaro Miranda Benito, Arturo Villanueva López y Emeterio García Juárez, donde se transmitían las susodichas órdenes del gobernador. Al lado, una marca en aspa, a modo de " $X$ », sintomático de que no había prosperado, en el último instante, intercesión alguna.

Y es que, por más que un documento certificado avalaba expresamente que habían sido puestos en libertad y que, incluso, así figurase en los expedientes procesales con una anotación manuscrita inequívoca en este sentido, el destino que les esperaba no era precisamente la calle. De modo que, de acuerdo con los planes de actuación previamente establecidos, estos eran entregados a las fuerzas de orden público, a la sazón, piquetes constituidos por miembros de las milicias mencionadas, toda vez que se les había investido de tal autoridad por designio de los militares. Este mecanismo de actuación, hasta cierto punto protocolizado, matiza, a nuestro modo de ver, esa autonomía que generalmente se le ha atribuido a los grupos de milicianos fascistas y carlistas a la hora de perpetrar sus crímenes. No en vano, junto a ellos era frecuente que oficiales de la Guardia Civil asumiesen, también, un destacado papel a la hora de organizar las sacas, como, por ejemplo, ocurriese con el capitán Enríque García Lasierra y el cabo Mariano Vián Antolín, responsables de los traslados efectuados de gente de la Ribera del Duero y del Valle del Arlanza, o del teniente Julio Martínez Hernáiz en la zona de Pinares.

Es importante subrayar que las tandas de «liberados» se organizaban agrupándolos en función de sus lugares de origen. Casuística que constatamos en las sacas producidas en los penales oficiales de Burgos, pero también en las cárce-

14 Ibidem, p. 168. 
les improvisadas de Aranda de Duero y Salas de los Infantes. Eran sacados, por tanto, para ser conducidos, supuestamente, a sus casas. Cierto es que, en otras ocasiones, pensaban que iban a ser trasladados a otras prisiones como, por ejemplo, al conocido fuerte de San Cristóbal en las cercanías de Pamplona o bien a Vitoria. Sendos procederes explica que muchos de los parajes donde terminarían siendo asesinados estuviesen junto a las carreteras que iban en esas direcciones, pero sobre esto volveremos más adelante. Habría que decir que cuando estas salidas se hicieron cotidianas, los presos encerrados dejaron de creer que iban a ser liberados o reubicados. De hecho, a través de las cartas que enviaban a sus familiares, se puede apreciar cómo, muchos de ellos, sabían ya del trágico final que les aguardaba.

Hay que añadir que siempre eran custodiados por guardia civiles e, incluso, a veces, acompañados por pequeños retenes de soldados como ocurrió en el Monte de Estépar donde el comandante José Íñigo figuraba al mando del destacamento. Y es que la presencia y participación de todos ellos en tales ejecuciones ha quedado bien demostrada a la luz de la munición encontrada a pie de muchas fosas, así como en el interior de las mismas. Se trata de casquillos y proyectiles de armas cortas y largas, pero, en todo caso, reglamentarias que delatan su inequívoca participación.

A tenor del número de víctimas que componían cada saca, dato observado en la documentación anteriormente referida del penal burgalés, pero también en las fosas excavadas, se sabe que eran pequeños grupos, por lo general, de no más de una docena de presos, aunque a veces lo superaban con creces como los que fueron a parar al Monte de Estépar. El registro bio-arqueológico también nos confirma que muchos de ellos estaban maniatados, puesto que aparecen con las muñecas juntas o bien porque se han llegado a conservar restos de las ligaduras. De modo que cabe pensar que eran subidos a las camionetas y a los autobuses que se emplearon para trasladarles, bien atados individualmente o de dos en dos, tal y como nos han informado, en ocasiones, las fuentes orales. Estas abundan, igualmente, en el hecho de que salían de madrugada. Se puede decir que para ocultárselo a los familiares, pero también a la población afecta, pues era una forma de evitar su conocimiento público.

Una vez llegaban a los sitios convenidos eran bajados de los vehículos referidos y mandados formar en fila junto a las zanjas, tal como sugiere el rastro de vainas encontradas a pie de muchas fosas, las cuales, previamente, habían sido cavadas por ellos mismos o bien por quienes iban a resultar ser sus verdugos; testimonios de testigos les hay en sendos sentidos. Lo que escuchaban entonces los vecinos de las localidades de los entornos de estos parajes eran, como nos han contado en las entrevistas realizadas a supervivientes nonagenarios, las detonaciones estruendosas de los máuseres a la que seguían unas ráfagas secuenciadas de disparos de pistola que, como prueban los orificios ocasionados por los impactos de los proyectiles documentados en los cráneos de las víctimas, no eran sino tiros de gracia. 
Al amanecer, no era raro que los paisanos, camino de sus labores en el campo, se acercasen a comprobar el trágico escenario resultante de una noche de orgía sanguinaria. Había entonces quien rapiñaba los escasos efectos personales que de valor tenían algunas de las víctimas, tales como relojes o determinadas prendas que a los guardias de los penales se les había podido pasar por alto requisar o, incluso, a quienes integraban los pelotones de ejecución, dados también a despojarles de estas u otras pertenencias en los momentos previos a descargar la fusilería a discreción.

$Y$ es que actitudes y comportamientos depravados no faltaron por parte de estos últimos. Así, los relatos de torturas y vejaciones infringidos bajo estado de embriaguez, particularmente a reconocidas personas que había entre los presos, pronto trascendieron $y$, pasado el tiempo, se puede afirmar que se han revelado creíbles o, cuando menos, posiblemente veraces muchos de ellos. Mención aparte merece, en este sentido, el episodio vivido a mediados de agosto en el paraje de La Lobera, a las afueras de Aranda de Duero, donde una de sus vecinas -Ángela Rodrigo Berrojo conocida como «La Forosa»- quiso acompañar a su marido -Macario Rodríguez García- al saber que era sacado a ese lugar desde la cárcel local. Eso sí, fue asesinada en su presencia por sus captores, no sin antes haber sido, supuestamente, violada por estos mismos. Que, al parecer, estuviese en avanzado estado de gestación no pareció que fuese tampoco impedimento alguno para que se consumase tan execrable crimen ${ }^{15}$. En todo caso, durante los trabajos exhumatorios todo lo más que se pudo verificar fue la presencia de ambos, eso sí, yacían uno al lado del otro; lo que no deja de ser bastante revelador.

De modo que «flechas» y «pelayos», a costa de ir dejando cadáveres en las entrañas de los montes, se erigieron en los principales perpetradores de la represión franquista, los cuales, no conviene olvidar, recibían órdenes expresas de la pléyade de militares insurrectos. Así fue que, tan sanguinarias prácticas, se hicieron cotidianas a lo largo de los meses estivales como también de los otoñales. Hasta el punto de llegarse a ejecutar a cerca de un millar de simpatizantes republicanos recluidos en cárceles. El mes de septiembre sería, sin lugar a dudas, el más sangriento de todos ellos, pues alcanzará el cenit de asesinados en toda la provincia burgalesa. Por otro lado, que sus siniestras patrullas o escuadrones de la muerte en muchos casos recibiesen apelativos macabros del tipo «brigada negra ${ }^{16} \mathrm{O}$ "los hijos de la noche ${ }^{17}$, ilustra a la perfección la labor que desempeñaban por mor a esa patria que los militares sublevados, con Franco a la cabeza, estaban «purificando», además de «reconquistando», al tiempo que sentaban las bases de un sórdido nacionalcatolicismo que habría de perpetuarse en los 35 años siguientes bajo el designio dictatorial del «Caudillo».

15 J.M. ROJAS RUIZ: Semilla de libertad II. El expolio franquista. Eneida, Madrid: 2011, p. 58.

16 Ibidem, p. 62.

17 J. GUTIÉRREZ FLORES: Guerra Civil en Cantabria y pueblos de Castilla. Libros en red: 2006, p. 234. 


\section{Lo que la tierra esconde}

Llegados a este punto nos planteamos explorar los lugares que tuvieron por escenarios tales actos represivos que, en esencia, fueron matanzas masivas a tenor de las cifras de víctimas que arrojan las exhumaciones realizadas hasta la fecha. No en vano, de la magnitud de tal barbarie dan cuenta 12 parajes cuyas fosas han permanecido soterradas durante décadas hasta que, hace unos pocos años y al albor del fenómeno memorialístico, se han podido ir excavando gradualmente y, a veces, identificando los restos de muchas de las víctimas ${ }^{18}$. Así pues, agrupamos estas fosas atendiendo a los centros de confinamientos desde los cuales se produjeron las susodichas sacas (Fig. 1).
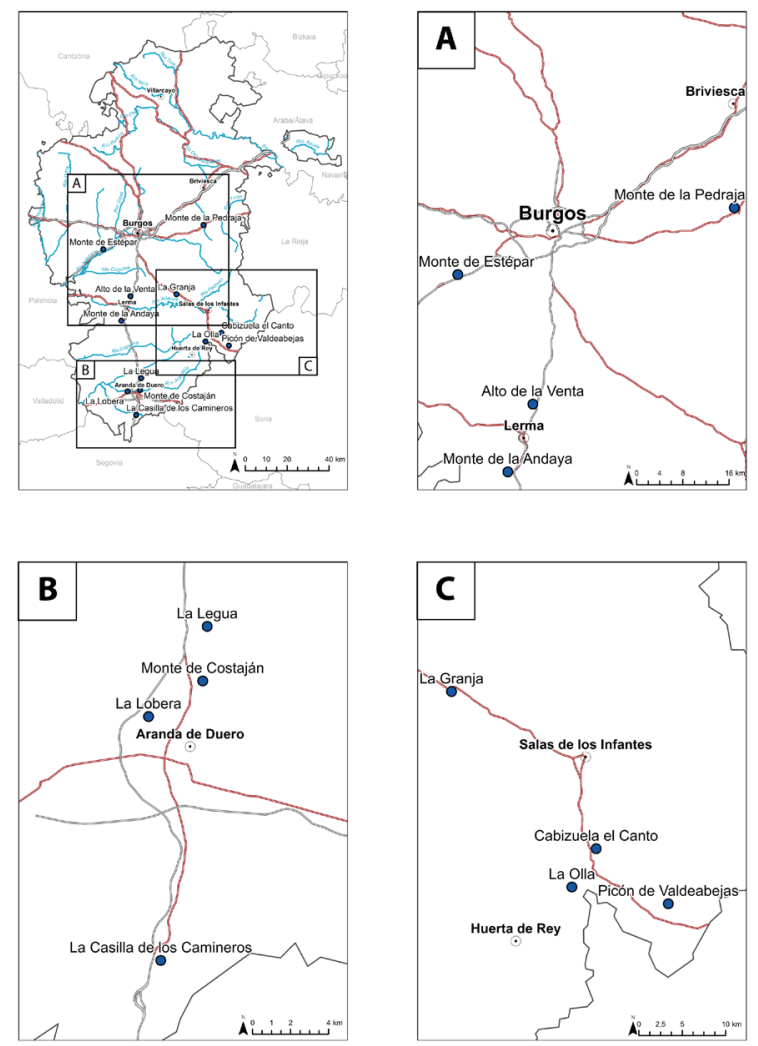

Fig. 1. Mapa de la provincia de Burgos con la ubicación de las fosas comunes producto de sacas de los centros de confinamiento de (A) Burgos, (B) Aranda de Duero y (C) Salas de los Infantes (Elaboración: A. Ibañez de Garayo).

18 Le estamos muy agradecidos a Francisco Etxeberría y Lourdes Herrasti de la Sociedad de Ciencias Aranzadi por haber tenido la amabilidad de facilitarnos los Informes Técnicos que han redactado de sus intervenciones en tierras burgalesas. 


\section{Las sacas de los penales de Burgos}

Especialmente numerosas fueron las sacas producidas en los penales de la capital burgalesa, esto son, la Prisión Central y la Provincial, por otro lado, las dos únicas oficiales que existían en toda la provincia de Burgos. De la primera sabemos que hubo, por lo menos, 19 desde que éstas se inician a comienzos del mes de agosto hasta que a mediados de octubre cesan. Entre medias, cerca de 400 presos fueron falsamente excarcelados. En el caso de la segunda, lo cierto es que muy poco es lo que se ha podido conocer al respecto, pues no se ha conservado apenas documentación al contrario de lo ocurrido con la Central. Aun así, se tiene constancia de alguna saca.

De manera que nos vamos a referir, básicamente, a los sacados desde la Prisión Central. De ellos se sabe que fueron conducidos hasta, al menos, cinco lugares diferentes. Estos estaban muy distanciados entre sí, toda vez que se localizaban en direcciones opuestas, concretamente junto a las principales vías o arterias que salían de la capital burgalesa hacia Logroño, Madrid, Valladolid y Vitoria. Tales emplazamientos, lejos de ser casuales, respondían a diferentes dinámicas de salidas de los presos.

Así, en primer lugar, a quienes creían ser trasladados a los penales de Vitoria o del fuerte de San Cristóbal en Pamplona para efectuar diligencias o por estar saturado el penal burgalés, en realidad, les apeaban en el Monte de La Brújula o bien de La Pedraja. Si bien del primero se desconoce la ubicación exacta de las fosas, puesto que el paraje ha sufrido notables alteraciones, incluso desde entonces ${ }^{19}$; en cambio, del segundo se localizaron dos fosas longitudinales de gran envergadura que fueron excavadas en los años 2010 y 2011 a cargo de la Sociedad de Ciencias Aranzadi. En total se pudieron recuperar los restos de un total de 134 individuos, distribuidos 104 en una y 31 en otra, si bien de nuevo aquí las obras realizadas, apenas unos años antes, de una pista para acceder a este monte arrasaron parcialmente la segunda de estas fosas, desconociéndose, en consecuencia, el número exacto de víctimas que pudiese haber.

Llama la atención que de todas ellas, tan solo 11, la mayoría de Miranda de Ebro, procediesen del penal burgalés, concretamente de una saca fechada el 3 de octubre de $1936^{20}$. El resto procedían, sobre todo, de paseados de localidades próximas pertenecientes a La Rioja como Herramélluri (el 20 de julio), Tormantos (26 del mismo mes), Castañares (18 de agosto), Grañón (11 de septiembre) y Santo Domingo de la Calzada (en noviembre) ${ }^{21}$, habiendo también un grupo muy

19 A las obras de ampliación de la actual carretera N-I que cruza el citado monte de La Brújula se debe sumar la construcción de la Autopista A-1 que discurre en paralelo. Pero es que ya en el año 1937 se llevó a cabo la repoblación de este paraje con la plantación de pinos que trajo consigo la consiguiente alteración del subsuelo.

20 I. RILOVA PÉREZ: op. cit., 2001, p. 193.

21 J.V. AGUIRRE GONZÁLEZ: Aquí nunca pasó nada. La Rioja 1936. Ochoa, Logroño: 2007. 
numeroso de gente de Miranda de Ebro y pueblos aledaños -se desconocen las fechas-, así como de la comarca de la Bureba; estos últimos habían destacado por sus posiciones políticas, siendo sacados de la cárcel de Briviesca el 26 de agosto, a tenor de los testimonios recopilados por la Agrupación de Familiares de las Personas Asesinadas en los Montes de La Pedraja ${ }^{22}$. El problema viene dado porque en los procesos de exhumación se han diferenciado 19 tandas entre sendas fosas, por lo que es, muy probable, que hubiese muertos de otros muchos municipios burgaleses como riojanos.

Pero, al margen del origen de las víctimas que, por cierto, se han podido identificar más de una docena de ellos gracias a los análisis genéticos, posiblemente haya que reflexionar sobre el porqué de que una única saca saliese del penal burgalés en dirección al Monte de La Pedraja, cuando era, como se ha visto, un paraje que ya venía siendo utilizado desde hacía semanas. ¿Tal vez influyó que las víctimas de esa saca fuesen, principalmente, mirandeses y muchos de sus convecinos ya habían ido a parar allí producto de paseos? o ¿cabe pensar que fue La Brújula, y no La Pedraja, el lugar fijado preferentemente para llevar a reclusos de la Prisión Central o bien de la Provincial que pensaban iban a cambiar de centro de confinamiento? Es muy difícil llegar a otra conclusión, de momento, a la vista de que no se han podido localizar las fosas que, supuestamente, alberga el citado monte, pero bien puede ser una línea de investigación que se deberá explorar con el tiempo.

Ahora bien, si hubo un lugar donde se sacaron de forma reiterativa a los presos, este fue el Monte de Estépar. Es por ello que, desde entonces, ha supuesto un estigma para sus vecinos que siempre han preferido guardar silencio al respecto, a pesar de las continuas visitas de familiares que, verdaderamente, no siempre estaban seguros de tener allí a sus deudos, pero que acudían con la esperanza de depositar, al menos, un ramo de flores con el que poder honrar la memoria de los mismos, o de los actos de homenaje celebrados, a iniciativa de militantes socialistas, cada 1 de noviembre tras la muerte de Franco. $Y$ es que el pueblo de Estépar es conocido en toda la provincia burgalesa, precisamente, por estos funestos episodios. Solo recientemente, al amparo de las campañas de exhumación que hemos llevado a cabo en julio de 2014 y abril de 2015, se ha podido percibir una indudable apertura a la hora de hablar con los foráneos y trasmitirles sus recuerdos, no exenta, eso sí, de cierta prudencia por parte de las generaciones que entonces eran unos críos y hoy nonagenarios. Así pues, la trascendencia del paraje aconseja detenerse a analizar con un poco más de detenimiento el proceso represivo seguido.

Hasta 13 sacas con un total de 285 «liberados» hemos podido documentar en el marco de nuestras investigaciones sobre los desaparecidos en este enclave

22 Queremos reconocer de manera especial a su presidente, Miguel Ángel Martínez Movilla, su determinación en la incansable búsqueda de las fosas de La Pedraja, así como su dedicación a mantener viva la memoria de quienes allí fueron asesinados e inhumados. 
ubicado a escasos $21 \mathrm{~km}$ de Burgos; aunque, en ocasiones, no sea fácil determinar con exactitud si fueron a parar allí o a un lugar distinto. Puede considerarse indicativo que, hasta la fecha, hayan sido recuperados 96 cuerpos sin que, por el momento, se haya podido conocer con certeza sus identidades y fechas de muerte. No obstante, lo reciente de esta actuación, nos hace ser cautos, pero también esperanzadores en este sentido. Aun así, la ya mencionada documentación oficial del penal burgalés nos ha legado una detallada relación nominal de las víctimas, así como de los días en que fueron supuestamente sacados.

En virtud de ello sabemos que procedían de prácticamente todos los rincones de la provincia burgalesa, aunque, en rigor, cerca de un centenar eran naturales de la ciudad de Burgos. Relativamente numerosos eran también los grupos de vecinos de Castrojeriz y Melgar de Fernamental, así como de localidades serranas, cuál era el caso de Palacios y Quintanar de la Sierra o, incluso, más lejanas como Medina de Pomar. En todo caso, la geografía del terror en el Monte de Estépar estaba representada por víctimas de multitud de pequeñas poblaciones donde la represión se había llevado a cabo con igual intensidad que en los núcleos grandes.

Por otro lado, a la luz de las tareas de complementación documental hechas a partir de dicha fuente, se ha podido confirmar la presencia de un gran número de afiliados a las formaciones políticas y sindicales integrantes del Frente Popular: desde quienes se distinguieron por su activismo a través de los comités de las Casas del Pueblo o las sociedades obreras de distintos municipios hasta quienes pertenecían a las mismas por el simple hecho de poderse ganar un jornal y que por ello, se puede decir, nunca habían destacado por su significación política. Figuraban, sin ir más lejos, sus máximos dirigentes en la capital burgalesa, arrojando, en este caso, un siniestro balance entre las filas de sus organizaciones con 17 socialistas asesinados, 13 del JSU, 8 de Acción Republicana y otros tantos de Izquierda Republicana, 6 del Partido Comunista y 3 del Partido Republicano Radical Socialista, además de 33 de UGT y 14 de la CNT. Se debe señalar que había, también, algunos ediles y concejales de otras localidades, además de los diputados provinciales Luis Díez Pérez e Isaac Pagazaurtundua Aguirre, e, incluso, quien fuera el Gobernador Civil, Julián Fagoaga Reus, probablemente la persona con el cargo más relevante entre quienes fueron asesinados.

No obstante, todos ellos aparecen ensombrecidos por la figura del insigne compositor Antonio José Martínez Palacios que suele considerarse la personalidad más ilustre, no ya sólo por lo que representaba en el ámbito de la música burgalesa de entonces (y ahora) sino, a fin de cuentas, como intelectual en aquel Burgos que rezumaba conservadurismo por los cuatro costados. Y lo mismo se puede decir de su hermano Julio que fuera maestro y periodista, al igual que Antonio Pardo Casas, director de la revista Burgos Gráfico donde el propio Antonio José, íntimo amigo suyo, era un asiduo colaborador. Quien tampoco pudo escapar y como los anteriores acusaba de cierta relevancia intelectual fue Francisco 
Ayala Arroyo -padre del reconocido escritor que llevase su nombre- que, como funcionario de Patrimonio Nacional, ostentaba el cargo de administrador del Monasterio de Las Huelgas Reales; lo que explica su estancia en tierras burgalesas, pues era andaluz. Que todos ellos fueran republicanos convencidos, más allá de si estaban o no afiliados a alguna de las organizaciones anteriormente señaladas, no deja lugar a dudas sobre las motivaciones ideológicas que había tras sus muertes, por más que pudiesen mediar denuncias anónimas de terceros como, al parecer, les ocurrió a Antonio José y a Pardo Casas. Qué duda cabe que no fueron los únicos, pues muchos más correrían idéntica suerte de terminar trágicamente en el Monte de Estépar.

En este punto debemos hacer referencia al tema de las fechas, pues la primera de las sacas se produjo el 2 de agosto y no fue, al parecer, hasta comienzos del mes de septiembre que se retomaron las mismas, eso sí, de forma ya prácticamente ininterrumpida hasta el 12 de octubre que, como es sabido, cesan definitivamente. Semejante trasiego de traslados como el elevado número de ejecuciones precisaba, evidentemente, de una mayor coordinación de la que aparentemente se pueda pensar. Tal es así que, con el paso del tiempo, han aflorado los testimonios, relatados por supervivientes de la época que, entonces, eran vecinos de los pueblos del entorno, los cuales nos han ayudado a conocer el modus operandi. De modo que ahora sabemos que las fosas estaban preparadas de antemano por un retén de falangistas que solían acudir a almorzar con posterioridad a la cantina de Estépar donde esperaban hasta que, a medianoche, se producía la llegada de los presos custodiados por militares a los que luego acompañarían al lugar convenido bajo el mando de un oficial, el ya mencionado comandante José Íñigo. El trayecto, a tenor también del relato de Ruiz Vilaplana, lo hacían en autobuses, estando generalmente atados ${ }^{23}$. Extremo éste en el que abundan los testigos entrevistados.

Probado queda que hubo tal grado de organización que a la vista está que las fosas no se cavaron arbitrariamente en cualquier lugar. Precisamente, respecto a los emplazamientos donde se iban a efectuar las ejecuciones y los enterramientos, tenemos constancia de que se encontraban dispersos por todo este vasto paraje, si bien cabe hablar de cuatro sectores donde se concentrarían la mayoría, sino la totalidad, de las fosas. No es difícil imaginar que buscaron las zonas donde el terreno era más blando y, por tanto, fácil de excavar.

De ahí que uno de los sitios escogidos fuese, en esencia, un arenal ubicado a pie del monte, junto a la carretera que conduce a la localidad de Villagutiérrez. Lamentablemente, la extracción de dicho material, en los años 60, a cargo de particulares primero y luego una empresa, propició el hallazgo de numerosos restos óseos, al parecer, humanos, pero también ocasionó la consiguiente desaparición

23 A. RUIZ VILAPLANA: Doy fe... Un año de actuación en la España nacionalista. Espuela de Plata, Sevilla: 2012, p. 136. 
de los mismos, tal como nos han confirmado los propios vecinos de las localidades próximas, y por tanto, sin que podamos saber el grado de afección sobre el conjunto de fosas que debía haber allí. Todo lo contrario que en los terrenos yermos que coronan el monte, en rigor, la única parte de este promontorio que se ha preservado de las alteraciones paisajísticas que han ocasionado diversas actuaciones acometidas desde los años 80 en adelante y que, a tenor de los testimonios de operarios que trabajaron en su día, habrían provocado la destrucción y desaparición de más fosas.

De modo que en la parte no afectada se localizaron un total de cuatro fosas, hallándose los restos de 96 víctimas distribuidas en función de las sacas producidas. En este sentido, conviene subrayar el hecho de que contenían cifras similares con 27 cuerpos una de ellas y 26 otras dos, si bien una cuarta albergaba 17. Las similitudes observadas alcanzan también a la colocación de los cuerpos que se acumulaban sin orden aparente, en muchos casos superpuestos y con numerosos orificios y fracturas ocasionadas por los impactos de proyectiles de armas de fuego.

En todo caso, aquí se percibe, una vez más, que los militares estaban detrás de tal labor represiva, pues las fosas referidas no se distribuyen aleatoriamente en el espacio, sino que siguen un patrón hasta cierto punto metódico, pues al hecho de que se disponen alineadas entre sí, se une que tienen un tamaño muy similar, lo que abunda, insistimos una vez más, en como de planificado lo tenían y la sistematización de la práctica. No en vano, en la mayoría de las sacas que tenemos documentadas figuraban del orden de 25 presos, lo que ayuda a entender que hubiese unas pautas fijadas previamente respecto a la forma y envergadura que debían tener las fosas y, por razones evidentes, que condiciones debían reunir los sitios elegidos para perpetrar tales matanzas de manera continua y recurrente $y$, a su vez, ocultárselo a los habitantes de las poblaciones aledañas.

Como hemos visto, esto último no fue posible, aunque, lógicamente, si consiguieron atemorizarles en un ambiente de terror ya de por sí generalizado. Prueba de ello es que se instaló el miedo, además de un largo silencio que ha acompañado a muchas de las generaciones de vecinos de las localidades del entorno próximo del Monte de Estépar. Que se explica, todo hay que decirlo, no sólo por la existencia de episodios dolorosos relacionados con los recuerdos que esas imágenes del tránsito de los autobuses rumbo a lo alto del monte evocaban, sino también con otros de carácter más oscuro por la colaboración que prestaron algunos vecinos, no siempre obligados.

Detengámonos ahora, aunque más brevemente, en los otros dos parajes donde fueron sacados presos de los penales burgaleses. Como se señalaba en el apartado previo, la extendida práctica de reclamar la puesta en libertad de ciertos presos por parte de falangistas o de los mandos de la Guardia Civil hacía que, finalmente, partidas integradas por estos elementos armados acudiesen hasta las mismas puertas de los centros penitenciarios para conducirles de vuelta. Esto 
constituye, hasta cierto punto, una variante respecto los dos casos examinados anteriormente. Que les hiciesen creer que iban a ser trasladados hasta sus localidades de origen explica que acabasen en el Alto de la Venta en Villamayor de los Montes o en el Monte de La Andaya en las proximidades de Lerma, puesto que las víctimas eran, en su mayoría, oriundas del Valle del Arlanza y de la Ribera del Duero y estos parajes se encontraban, precisamente, de camino a estas comarcas.

La maquinaria represiva se puso en marcha el 25 de agosto con una saca de 29 individuos, sucediéndose con posterioridad otra el 5 de septiembre con 15 más y hasta una tercera el día 11 de ese mismo mes con 41 presos. Lo que hace un total de 85 cuerpos repartidos en tres fosas que el equipo de la Sociedad de Ciencias Aranzadi excavó entre los años 2006 y 2007. Las tierras donde se perpetraron estos asesinatos, ubicadas a pie del Monte de La Andaya, pertenecen, en realidad, a Quintanilla de la Mata, localidad cercana a Lerma de cuya cárcel provenían, precisamente, algunas de las víctimas. Pero sabemos con certeza que la mayor parte de quienes reposaban allí eran vecinos de Aranda de Duero, más de medio centenar entre los que estaban su alcalde, Felipe Gutiérrez Catalá, y seis de sus concejales pertenecientes, naturalmente, al Frente Popular. No serían los únicos significados políticamente. Prendidos en los primeros días que sucedieron a la sublevación, rápidamente fueron enviados no sólo a la Prisión Central de Burgos, sino también a la Provincial, pues algunas de las salidas de este penal también dejaron huella documental. No parece aventurado pensar que las dos mujeres halladas en este paraje fuesen, probablemente, reclusas de este penal, puesto que, como ya señalamos, era mixto.

Un hecho éste de juntar «liberados» de diferentes penales que se repetiría en el caso de los que fueron conducidos al Alto de la Venta a escasos metros del núcleo de Villamayor de los Montes y donde un equipo de la Universidad Autónoma de Madrid Ilevó a cabo en el año 2004 la correspondiente exhumación de una fosa donde se hacía palpable la existencia de dos tandas bien diferenciadas ${ }^{24}$. Concretamente, las víctimas formaban parte de sendas sacas del primero de los penales burgalés referido, fechadas el 13 de septiembre y el 24 de ese mismo mes, con 25 y 21 presos respectivamente, lo que hace un cómputo de 46. Pero entre los integrantes de la primera figuraban, al menos, ocho de la cárcel de Lerma.

De modo que vemos como fue habitual incrementar la nómina inicialmente prevista de sacados, lo que, por extensión, no sólo elevaba la cifra ya de por sí considerable de víctimas, sino que, pasado el tiempo, ha terminado dificultando el conocimiento de la relación de personas que hicieron el recorrido hasta estos dos parajes. Así sucedió que las tareas de identificación han sido sumamente complejas, habiéndose obtenido muy pocos casos de análisis genéticos positivos ${ }^{25}$.

24 A. FUENTES DOMÍNGUEZ: "Exhumació i arqueología forense. Els afusellats a Villamayor de los Montes (Burgos)". L’Avenç, 299 (2005), pp. 28-30.

25 L. RÍOS FRUTOS: “Identificación en fosas comunes de la Guerra Civil: limitaciones y posibi- 


\section{Las sacas de la cárcel de Aranda de Duero}

De la gran cantidad de asesinatos cometidos en la Ribera del Duero da cuenta un sinfín de parajes diseminados por toda esta comarca. En cambio, los grupos de sacados de la cárcel de Aranda de Duero se concentran en tres parajes de los alrededores de la capital ribereña, en concreto, en el Monte de Costaján, La Lobera y La Legua; al que habría de sumarse un cuarto, La Casilla de los Camineros, más alejado, por cuanto se localiza en el término de Milagros. No era infrecuente que, además de los encarcelados, hubiese paseados, lo que nos consta por varios testimonios de familiares. Los hallazgos de ciertos objetos en las exhumaciones se tornan, entonces, vitales, pues constituyen los mejores indicios de si pasaron o no por la cárcel. Pensemos en enseres de uso cotidiano en estos contextos como, por ejemplo, cucharas, espejos, liendreras, mondadientes, etc. De la misma forma que la ausencia generalizada de pertenencias de valor también sugieren un confinamiento más o menos prolongado en el tiempo.

No sabemos exactamente qué criterios utilizaron para elegir unos u otros destinos, máxime cuando todas las sacas remiten, al parecer, al mes de agosto, con la excepción de las que se producen en septiembre, en cuyo caso fueron a parar, exclusivamente, a La Casilla de los Camineros. Pero, a decir verdad, son otras particularidades las que impiden saber quiénes fueron muchas de las víctimas. Y es que el principal escollo viene determinado por el elevado número de muertos que hubo entre los trabajadores de un sector en particular: los ferroviarios. Que su presencia sea realmente significativa responde al hecho de que, por entonces, se estaba construyendo la línea del ferrocarril directo Madrid-Burgos a su paso, precisamente, por la capital de la Ribera, donde, a su vez, enlazaba con el trazado de la línea Valladolid-Ariza en funcionamiento desde hacía tiempo. De modo que fueron muchos los operarios que llegaron desde otras provincias para trabajar en lo que se preveía que iba a ser un importante nudo ferroviario. Además, a ellos cabe añadir maquinistas y jefes de las estaciones del entorno, la mayoría de ellos militantes de la CNT y UGT, que tras ser prendidos habían sido confinados en la cárcel de Aranda.

Prueba de todo ello es que en la exhumación que llevamos a cabo en el año 2004 en el pago de La Lobera donde se encontraron los restos de 46 personas, también se recuperaron diversos objetos asociados a individuos que los relacionan, inequívocamente, al citado gremio. Algunos tan elocuentes como carnets de ferroviarios o insignias con los distintivos y emblemas del Regimiento de Zapadores Ferroviarios, esto es, el cuerpo del Ejército dedicado a la infraestructura del ferrocarril. Se trataría, concretamente, de una chapita que reproducía una locomotora y dos alfileres con la torre del arma de ingenieros (un castillo donjonado, almenado y mampostado). Estas insignias de la torre las Ilevaban puestas en

lidades a partir del caso de Burgos". Boletín Galego de Medicina Legal e Forense, 18 (2012), pp. 125-142. 
la solapa del uniforme, así como en la característica gorra de plato que portaba el personal ferroviario, mientras que la de la locomotora se ponía a la altura del pecho.

Por otro lado, en la fosa de La Legua se cree que de los 59 cuerpos exhumados por la Sociedad de Ciencias Aranzadi en 2011, la mayoría pertenecerían a trabajadores del ferrocarril. No obstante, las dudas que hay al respecto vienen dadas porque, a pesar de que se le conoce con el sobrenombre de la «fosa de los ferroviarios», a escasos 300 m, concretamente en el Monte Costaján, se localizan más fosas donde también se tiene la sospecha de que allí habrían ido a parar muchos de estos empleados como señalan los miembros del equipo de la Universidad de Burgos que excavó allí hasta un total de 84 cuerpos en 2003.

Pero no sólo entre los ferroviarios hubo un gran número de víctimas. Muchos eran de un origen todavía más humilde, no en vano, había numerosos jornaleros, a tenor de los testimonios de familiares que apuntan en este sentido. Sin duda sufrieron semejante suerte en los parajes citados, pero también en el ya referido de La Casilla de los Camineros donde merced a la excavación realizada en el 2009, una vez más por la Sociedad de Ciencias Aranzadi, se pudo documentar hasta cinco tandas repartidas en dos grandes fosas, no en vano, se exhumaron 46 cuerpos.

Los interrogantes que se ciernen sobre la identidad de la mayoría de las víctimas de todos estos parajes no se han disipado, todavía, ante las dificultades que plantea el cotejo de ADN con posibles descendientes, pues ocurre que no sólo eran muchos de ellos oriundos de otros puntos allende la Ribera, sino que otros muchos familiares de los que sí que eran vecinos de la comarca burgalesa decidieron emigrar pronto a la vista de que nada les ataba allí más que continuar siendo humillados y vejados dada su condición de «hijos y mujeres de rojos». De modo que, en muchos casos, no queda ningún familiar en sus localidades de origen y conseguir localizarles se convierte en toda una odisea con resultados, la mayoría de las veces, frustrantes ${ }^{26}$.

\section{Las sacas de la cárcel de Salas de los Infantes}

El caso de las sacas producidas desde la cárcel de Salas de los Infantes resulta muy paradigmático pues, en rigor, el número de víctimas fue muy reducido y, por extensión, los lugares empleados para las ejecuciones se restringieron a una zona de la comarca de Pinares muy concreta. Que las cifras fuesen relativamente irrisorias se explica, en gran medida, porque la inmensa mayoría de las personas que fueron detenidas acabaron siendo enviadas a la Prisión Central de Burgos

26 A tan ímproba labor se ha dedicado durante años José María Rojas Ruiz de la asociación En Medio de Abril a quien le agradecemos la información proporcionada sobre los lugares donde fueron ejecutados y las fosas en las que fueron enterradas las víctimas de la Ribera del Duero. 
desde donde saldrían, bien recobrando la libertad o bien con destino al Monte de Estépar.

No en vano, como resultado de uno de estos traslados, efectuado el 4 de septiembre, se produjo el asesinato de 6 vecinos de Castrillo de la Reina, incluido su alcalde, cerca de la localidad de Mambrillas de Lara. Desenlace que se explica, en realidad, porque en ese punto saltaron, del camión donde iban, otros dos de los reclusos que finalmente pudieron escapar. De modo que la represalia fue inmediata y sus compañeros terminaron siendo enterrados allí mismo como se pudo comprobar en la exhumación que realizamos en $2010^{27}$.
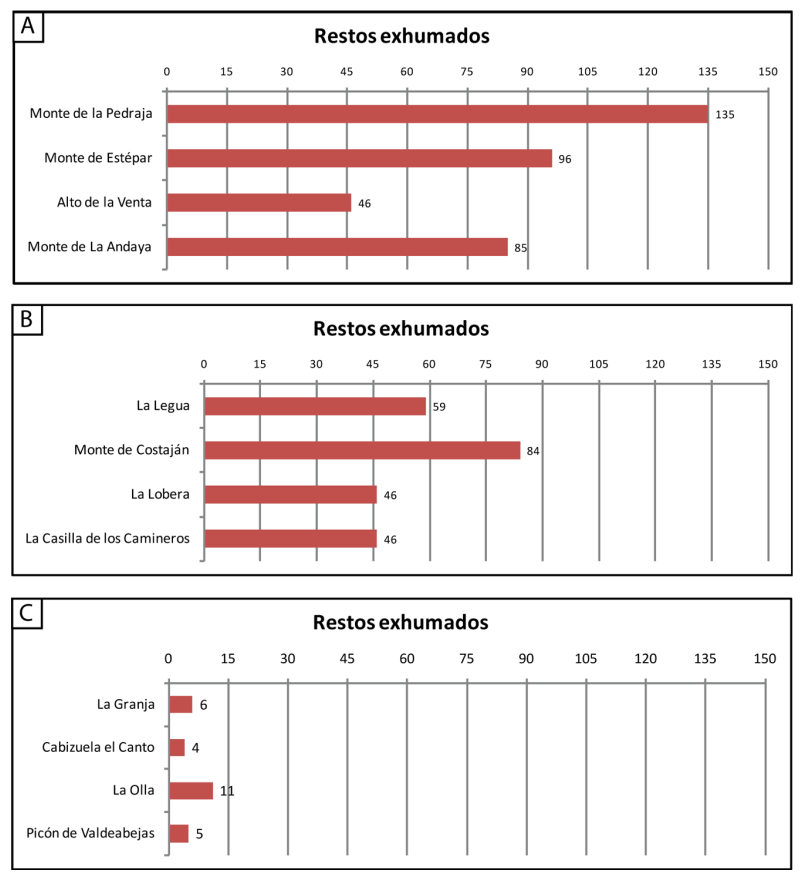

Fig. 2. Cómputo de cuerpos recuperados en las fosas comunes producto de sacas de los centros de confinamiento de (A) Burgos, (B) Aranda de Duero y (C) Salas de los Infantes (Elaboración: A. Ibañez de Garayo).

El resto, en cambio, sí que fueron sacados expresamente ${ }^{28}$. Así, en fechas prácticamente sucesivas a lo largo de ese mismo mes de septiembre se irían

27 J. MONTERO GUTIÉRREZ y E. VALDIVIELSO GUTIÉRREZ: "Claves metodológicas en el proceso de exhumación e identificación de los restos humanos de la fosa común de la Guerra Civil española de La Granja (Quintanilla de las Viñas, Burgos): aportes desde una perspectiva bio-arqueológica". Munibe (antropologia-arkeologia), 62 (2011), pp. 479-498.

28 Nuestro agradecimiento a Jesús Cámara Olalla por compartir la documentación referida a la represión en la comarca de Pinares y, en particular, por facilitarnos las fechas en que fueron sacados los diversos grupos de personas que habían sido confinados en Salas de los Infantes. 
liberando: los días 17 y 22 a dos grupos, uno de 5 vecinos de Mamolar y otro de 6 de Vilviestre del Pinar que terminarían en el paraje de La Olla, dentro del término de Pinilla de los Barruecos, en este caso, hemos de hacer mención que sus restos no pudieron recuperarse, pues estos se habían desintegrado completamente a causa de la acción del agua, tal como pudimos comprobar en el año 2011; el día 27 otro pequeño grupo de 5 personas de la comarca de Lara los dirigieron al enclave conocido como Picón de Valdeabejas en Rabanera del Pinar, estando sus restos, exhumados por la Sociedad de Ciencias Aranzadi en 2009, pendientes del estudio genético; y finalmente el día 2 de octubre a cuatro vecinos de La Revilla, cuya fosa localizada en el término conocido como Cabizuela el Canto, en Pinilla de los Barruecos, fue exhumada en 2010 también por la Sociedad de Ciencias Aranzadi.

Todos estos emplazamientos tenían en común que se trataban de zonas boscosas, propio, por otra parte, de esta comarca donde la masa de pinos es la tónica del paisaje serrano. Además, ni que decir tiene que entre las víctimas encontramos, nuevamente, varios ediles y concejales de evidente afinidad republicana.

\section{Consideraciones finales}

La principal característica de estos actos represivos que constituyen las sacas es que estaban organizadas desde arriba, es decir, desde las altas instancias militares. Y es que el procedimiento precisaba de la implicación de los mandos que ocupaban puestos claves en instituciones como el Gobierno Civil y los Centros Penitenciarios que después de lo visto a lo largo del texto no vamos a ahondar más en ello. Pero, a decir verdad, la maquinaria de terror precisaba de una amplia participación. Por un lado, de oficiales de menor graduación, ya fuesen miembros del propio Ejército como de la Guardia Civil encomendados, generalmente, a labores de coordinación como de custodia de los presos en los traslados. Y por otro, de los milicianos de Falange o del Requeté que se daban a las tareas no sólo de confeccionar, en muchos casos, las fatídicas listas, sino también de erigirse, en último término, en los verdugos, esto es, en los ejecutores que, sin reparo alguno, perpetraban las matanzas masivas que, en esencia, eran las sacas. Prueba de ello son los 623 cuerpos recuperados hasta la fecha, aunque el cómputo de víctimas sea probablemente superior, pues se sabe de la existencia de más fosas a pesar de no haber sido, por el momento, localizadas (Fig. 2).

Además, hay que apuntar la importancia que adquiere el paisaje, es decir, los parajes donde se cometían tales ejecuciones y, posteriormente, se enterraban a las víctimas. Como se ha visto a lo largo de este trabajo, se trataba, en la práctica totalidad de los casos, de lugares relativamente próximos a las cárceles desde donde irradiaban las sacas; con alguna salvedad que respondía a otro tipo de 
variante, pues supuestamente iban a trasladarles de prisión o bien a traerles de vuelta a sus localidades de origen, lo que explica la mayor distancia.

En cualquier caso, estaban ubicados junto a carreteras generales, pues así se garantizaba su fácil accesibilidad. Pero, no por ello hay que pensar que los cuerpos se abandonasen o enterrasen en las mismas cunetas como solía ser el procedimiento usual de los paseos. Más bien al contrario, es decir, se adentraban un poco, de modo que resultaban ser, al final, parajes recogidos, un tanto apartados, generalmente montes cubiertos de una tupida masa arbórea, lo que permitía ocultar a los habitantes de las localidades cercanas los crímenes que allí se cometían sistemáticamente una vez anochecía. Esto explica la elección recurrente de este tipo de enclave, en realidad, muy abundante en la provincia burgalesa, a pesar del marcado perfil amesetado que tanto caracteriza a esta tierra.

Por supuesto, otra de las razones para escoger estos emplazamientos tenía que ver con la facilidad que ofrecían para ser excavados. En primer lugar, porque abundaban los suelos arenosos en ellos y, segundo, porque generalmente son poco profundos. A fin de cuentas, eran prácticos, pues eran sabedores de que habían de cavarse muchas zanjas, a tenor de la «limpieza» que les habían encomendado.

\section{Bibliografía}

AGUIRRE GONZÁLEZ, J.V.: Aquí nunca pasó nada. La Rioja 1936. Ochoa, Logroño: 2007.

CASTRO BERROJO, L.: Capital de la Cruzada. Burgos durante la Guerra Civil. Crítica, Barcelona: 2006.

ESPINOSA MAESTRE, F.: "Julio de 1936. Golpe militar y plan de exterminio" en J. CASANOVA RUIZ (coord): Morir, matar, sobrevivir. La violencia en la dictadura de Franco. Crítica, Barcelona: 2002, pp. 51-119.

ESPINOSA MAESTRE, F. y CASTRO BERROJO, L.: "Prólogo" en A. RUIZ VILAPLANA: Doy fe... Un año de actuación en la España nacionalista. Espuela de Plata, Sevilla: 2012, pp. 11-49.

FUENTES DOMÍNGUEZ, A.: "Exhumació i arqueología forense. Els afusellats a Villamayor de los Montes (Burgos)". L'Avenç, 299 (2005), pp. 28-30.

GIL ANDRÉS, C.: "También hombres del pueblo. Colaboración ciudadana en la gran represión" en M.A. DEL ARCO, C. FUENTES, C. HERNÁNDEZ y J. MARCO (eds): No solo miedo. Actitudes políticas y opinión popular bajo la Dictadura Franquista (1936-1977). Comares Historia, Granada: 2013, pp. 47-63.

GÓMEZ BRAVO, G. y PÉREZ-OLIVARES, A.: "Las lógicas de la violencia en la Guerra Civil: balance y perspectivas historiográficas". Studia Historica. Historia Contemporánea, 32 (2014), pp. 251-262. 
GUTIÉRREZ FLORES, J.: Guerra Civil en Cantabria y pueblos de Castilla. Libros en red: 2006.

MONTERO GUTIÉRREZ, J. y VALDIVIELSO GUTIÉRREZ, E.: "Claves metodológicas en el proceso de exhumación e identificación de los restos humanos de la fosa común de la Guerra Civil española de La Granja (Quintanilla de las Viñas, Burgos): aportes desde una perspectiva bio-arqueológica". Munibe (antropologia-arkeologia), 62 (2011), pp. 479-498.

PRESTON, P.: El holocausto español. Odio y exterminio en la Guerra Civil y después. Debate, Barcelona: 2011.

RILOVA PÉREZ, I.: Guerra Civil y violencia política en Burgos (1936-1943). Dossoles, Burgos: 2001.

RÍOS FRUTOS, L.: "Identificación en fosas comunes de la Guerra Civil: limitaciones y posibilidades a partir del caso de Burgos". Boletín Galego de Medicina Legal e Forense, 18 (2012), pp. 125-142.

ROJAS RUIZ, J.M.: Semilla de libertad II. El expolio franquista. Eneida, Madrid: 2011.

RUIZ VILAPLANA, A.: Doy fe... Un año de actuación en la España nacionalista. Espuela de Plata, Sevilla: 2012. 